\title{
A CLINICOPATHOLOGICAL STUDY OF CERVICAL LYMPHADENOPATHY
}

\author{
Sanjenbam Shyamchand Singh ${ }^{1}$, Sougrakpam Robindro Singh ${ }^{2}$ \\ ${ }^{1}$ Assistant Professor, Department of Surgery, JNIMS, Imphal, Manipur. \\ ${ }^{2}$ Associate Professor, Department of Surgery, JNIMS, Imphal, Manipur.
}

\begin{tabular}{l}
\hline ABSTRACT \\
\hline BACKGROUND \\
In our country, cervical lymphadenopathy is a common manifestation where the incidence of tuberculosis and oral cancer is very \\
high. Therefore, the proper and early diagnosis of lymphadenopathy is very important for starting of early and effective treatment. \\
1. To conduct a clinicopathological study of cervical lymphadenopathy with regard to age, sex, clinical mode of presentation and \\
location of the lymph nodes. \\
2. To evaluate the accuracy of the Fine Needle Aspiration Cytology (FNAC) and histopathology.
\end{tabular}

\section{MATERIALS AND METHODS}

Fifty patients of both sexes above 15 years of age with cervical lymphadenopathy who attended in Regional Institute of Medical Science Hospital from November 2002 to November 2004 were studied prospectively. However, those patients with acute lymphadenitis who have already recovered after antibiotic treatment and did not require a diagnostic biopsy were excluded from the study. Detailed history taken and clinical examination conducted. The distribution of age, sex, mode of presentation and location of the cervical lymph nodes were recorded and whenever required routine investigations like complete ha emogram, urine analysis, chest x-ray, Mantoux test were performed. Fine Needle Aspiration Cytology (FNAC) was carried out according to the method of Franzen and Links (1983) followed by Excision biopsy in all the cases. These investigations were performed either as an outpatient procedure or as an inpatient procedure if already admitted in the ward.

\section{RESULTS}

In the present study, 35 cases (70\%) were benign lesions and 15 cases (30\%) were malignant lesions. Number of males with benign lesion were more. In benign lesion cases, 22 (62.8\%) were due to tubercular lymphadenitis and 13 (37.1\%) were due to Non-specific Lymphadenitis whereas in malignant lesion cases, 8 (53.33\%) were due to adenocarcinoma, 6 were (40\%) due to squamous cell carcinoma and 1 case (6.66\%) due to Non-Hodgkin's Lymphoma. Benign lesions were more common in the age group of 26-35 years $(42.85 \%)$ whereas malignant lesions were more common in the age group of 46-55 years (40\%). Neck swelling is the commonest presentation. Jugulodigastric group of lymph nodes were commonly involved in both benign and malignant conditions. Majority of the cases were successfully aspirated at first attempt. The results of FNAC were correlated with histology. Histopathology revealed 35 cases to be benign and 15 cases to be malignant while the cytology revealed 30 cases benign (85.5\%) and 13 cases malignant (86.6\%). Overall accuracy rate in cytology was $86 \%$. The accuracy rates for benign and malignant groups were $85.71 \%$ and $86.66 \%$ respectively.

\section{CONCLUSION}

Fine Needle Aspiration Cytology (FNAC) is a rapid, simple, safe, painless and cost effective procedure for early diagnosis and initiating better treatment of cervical lymphadenopathy without hospitalisation. However, aspiration cytology is not the substitute for histopathological examination but it is one of the weapons to be used to hit the diagnostic target.

\section{KEYWORDS}

Fine Needle Aspiration Cytology (FNAC), Cervical Lymphadenopathy, Clinicopathological.

HOW TO CITE THIS ARTICLE: Singh SS, Singh SR. A clinicopathological study of cervical lymphadenopathy. J. Evolution Med. Dent. Sci. 2016;5(86):6389-6394, DOI: 10.14260/jemds/2016/1445

BACKGROUND
Lymph nodes are peripheral lymphoid organs. The lymphadenopathy is a disease condition requiring further investigation with respect to its aetiology and diagnostic procedure. There are approximately 800 lymph nodes in the body. No fewer than 300 of them lie in the neck which are involved in the various pathological conditions. ${ }^{1,2}$

Financial or Other, Competing Interest: None.

Submission 22-09-2016, Peer Review 13-10-2016,

Acceptance 22-10-2016, Published 26-10-2016.

Corresponding Author:

Dr. S. Robindro Singh,

Singjamei Sougrakpam Leikai,

Imphal West-795008, Manipur.

E-mail: srobindro@yahoo.co.in, pradhineetaabc2009@gmail.com

DOI: $10.14260 /$ jemds/2016/1445
Cervical lymphadenopathy is defined as cervical lymph nodal tissue measuring more than $1 \mathrm{~cm}$ in diameter. ${ }^{3}$ Cervical lymphadenopathy is the commonest cause of a lump in the neck. It is usually secondary to acute infection. It can be present as an isolated feature or as a part of generalised lymphadenopathy. Disease affecting cervical lymph nodes are of varying severity starting from simple curable infection to difficult incurable malignant disease. The analysis of lymph node enlargement in the neck is not an easy task and the diagnosis of the condition is a problem because most of the diseases resemble each other. Improper diagnosis and treatment may convert a potentially curable disease into an incurable one. A swelling in the neck region can be a diagnostic challenge. The unfortunate patient has to undergo detailed investigative procedure which may be time consuming, traumatic and expensive. For cost effective, less traumatic, and 
accurate diagnosis of cervical lymphadenopathy, FNAC has an immense potential as reported in different leading serial publications. FNAC is an easy, minimally invasive, rapid and valuable diagnostic tool for the evaluation of cervical lymphadenopathy. 4,5

\section{Aims and Objective}

1. To conduct a clinicopathological study of cervical lymphadenopathy with regard to age, sex, clinical mode of presentation and location of the lymph nodes.

2. To evaluate the accuracy of the Fine Needle Aspiration Cytology (FNAC) and histopathology.

\section{MATERIALS AND METHODS}

Fifty patients of both sexes above 15 years of age with cervical lymphadenopathy who attended in RIMS Hospital during the period from November 2002 to November 2004 were studied prospectively. Those patients with acute lymphadenitis who have already recovered after antibiotic treatment and did not require a diagnostic biopsy were excluded from the study. Detailed history and clinical examination were taken. The distribution of age, sex and location of the cervical lymphadenopathy were recorded and whenever required routine investigations like complete haemogram, urine analysis, chest x-ray, Mantoux test were performed. Fine Needle Aspiration Cytology (FNAC) was carried out according to the method of Franzen and Links (1983) followed by Excision biopsy in all the cases. These investigations were performed either as an outpatient procedure or as an inpatient procedure if already admitted in the ward.

\section{RESULTS}

Fifty patients above 15 years of age have been taken for the study and diagnosis of the cases were proven histopathologically. The results and observations are in cooperated with tables and charts.

In the present study, 35 cases $(70 \%)$ were benign lesions and 15 cases (30\%) were malignant lesions as shown in table I. In benign lesion cases, $22(62.8 \%)$ were due to tubercular lymphadenitis and $13(37.1 \%)$ were due to Non-specific Lymphadenitis whereas in malignant lesion, 8 (53.33\%) due to adenocarcinoma, $6(40 \%)$ due to squamous cell carcinoma and 1 case $(6.66 \%)$ due to Non-Hodgkin's Lymphoma as shown in table II.

Out of 50 cases studied, there were 23 males $(65.71 \%)$ and 12 females (34.24\%) with benign lesions whereas with malignant lesions, there were 9 males $(60 \%)$ and 6 females (40\%) as shown in table III.

It was observed that benign lesions were more common in the age group of 26-35 years (42.85\%) which was followed by the age group of $15-25$ years $(28.57 \%)$ whereas malignant lesions were more common in the age group of 46-55 years $(40 \%)$ as shown in table IV.

The prominent clinical features observed in this study both for benign and malignant lesion patients were neck swelling (100\%), fever (42.85\% and $26.66 \%$ ), cough and expectoration (28.57\% and $13.33 \%)$, nasal problems (17.14\% and $6.66 \%)$, neck pain ( $11.42 \%$ and $20 \%$ ), difficulty in swallowing $(0 \%$ and $20 \%$ ) and lump with abdominal pain $(0 \%$ and $13.33 \%)$ which were shown in table $\mathrm{V}$.
Enlargement of Jugulodigastric lymph nodes was highest in both benign and malignant conditions with the percentage of $51.42 \%$ and $33.33 \%$ respectively as shown in table VI.

Bilateral involvement of nodes were found in 7 (14.00\%) cases and that of unilateral involvement on right side was 17 (34\%) cases and on left side was $26(52 \%)$ cases. It was observed that unilateral involvement nodes were more common with $86.00 \%$ (43 cases) as shown in table VII.

During aspiration, majority of the cases were successfully done at first attempt in 40 cases $(80 \%)$ whereas in 10 cases (20\%) second attempt of aspiration was required as shown in table VIII. The nature of aspiration was blood in 4 cases, scanty material in 3 cases whereas in 43 cases aspirate gives some diagnosis.

The results of FNAC were correlated with histology. Histopathology revealed 35 cases (70\%) to be benign and 15 cases $(30 \%)$ to be malignant while the cytology revealed 30 cases were benign $(85.71 \%)$ and 13 cases were malignant $(86.6 \%)$ as shown in table IX. Overall accuracy rate in cytology was $86 \%$.

The complications came across during the study by FNAC were minimal in comparison to open biopsy.
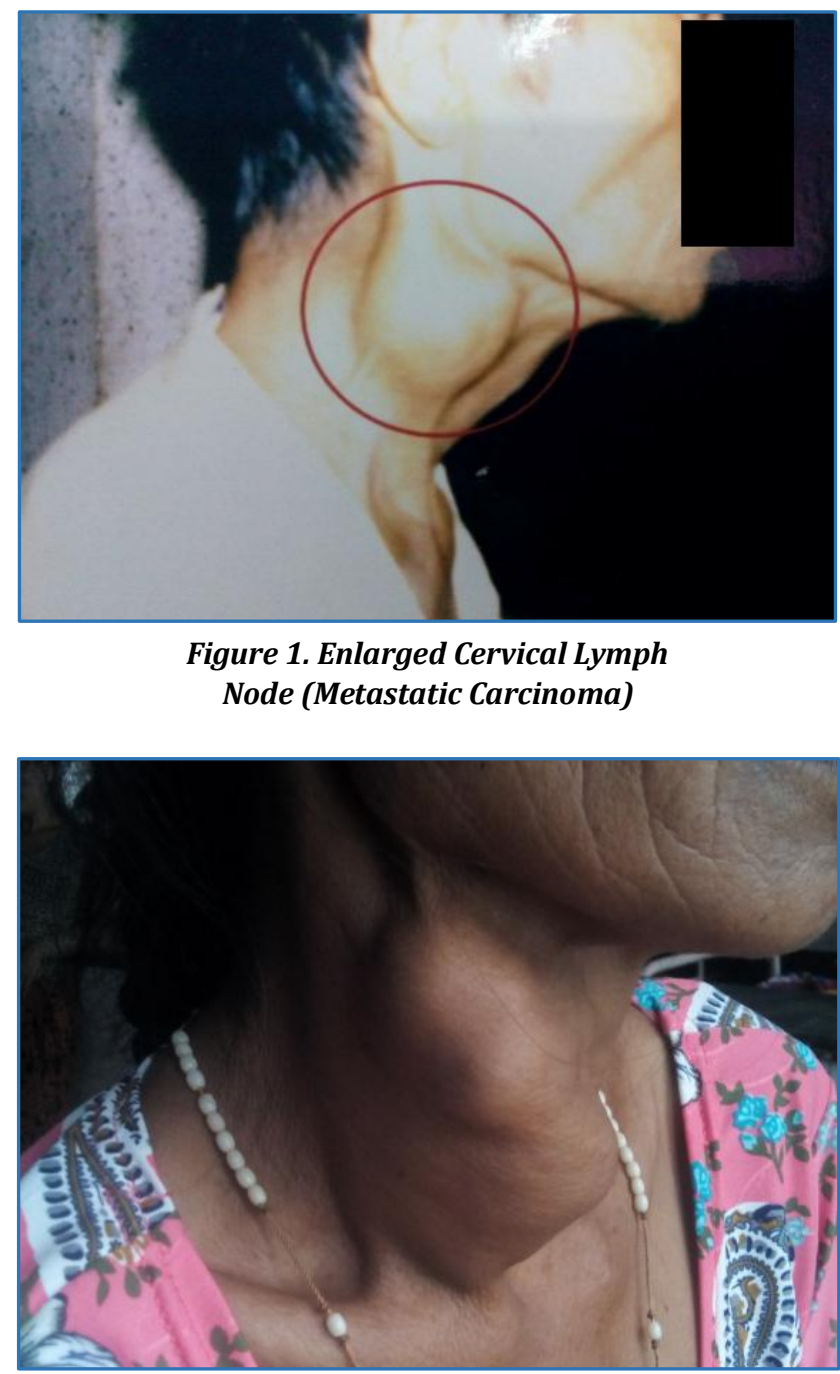

Figure 2. Enlarged Cervical Lymph Node (Metastatic Carcinoma) 


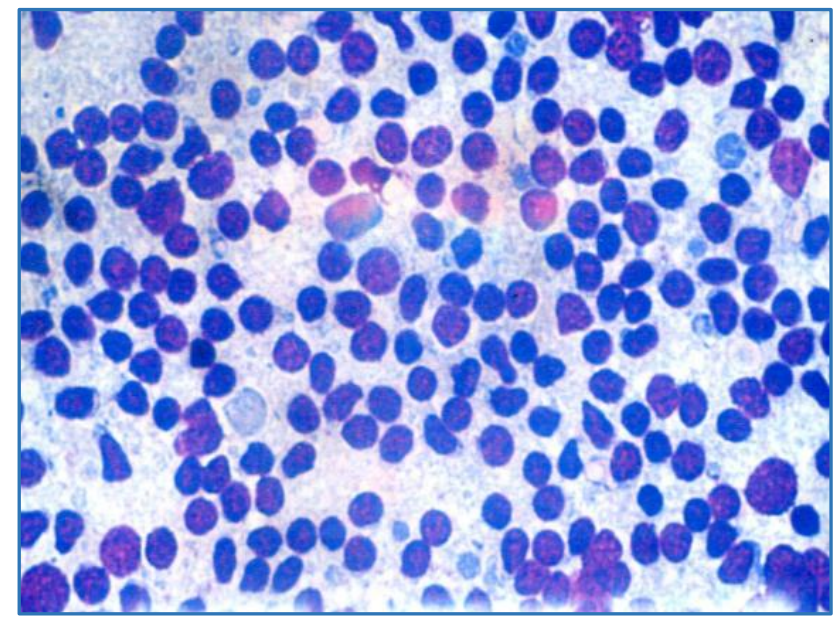

Figure 3. FNAC Smear showing Chronic Nonspecific Lymphadenitis

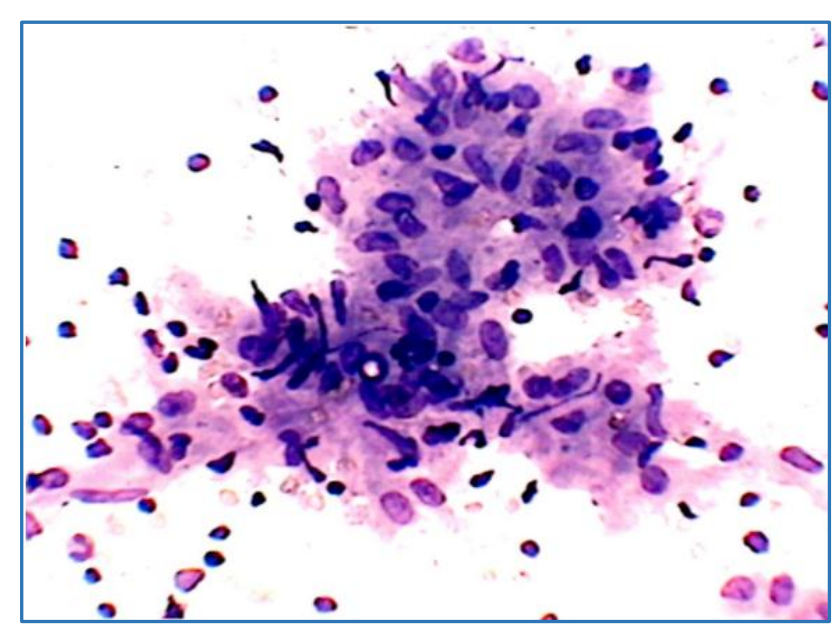

Figure 4. FNAC showing Epithelioid Granuloma (Tuberculosis)

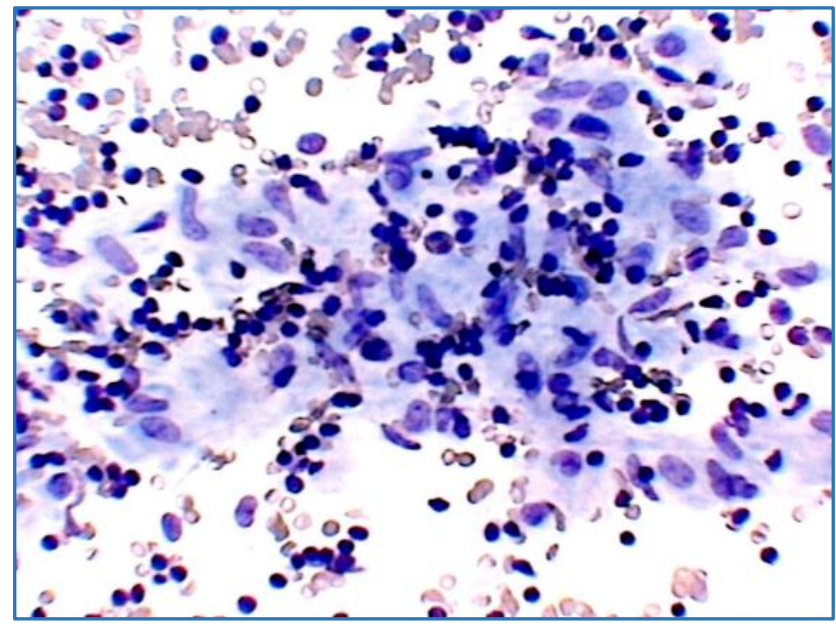

Figure 5. FNAC showing Epithelioid Granuloma (Tuberculosis)

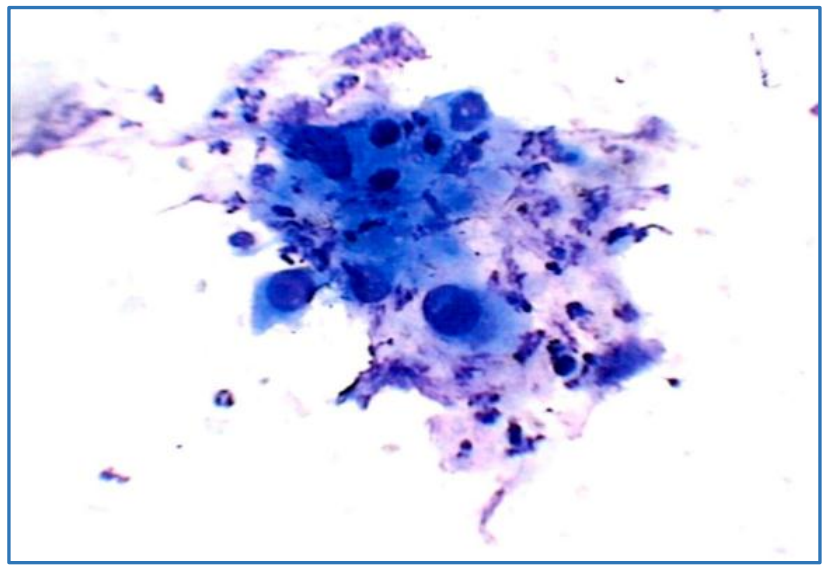

Figure 6. FNAC showing Metastatic Keratinising Squamous Cell Carcinoma

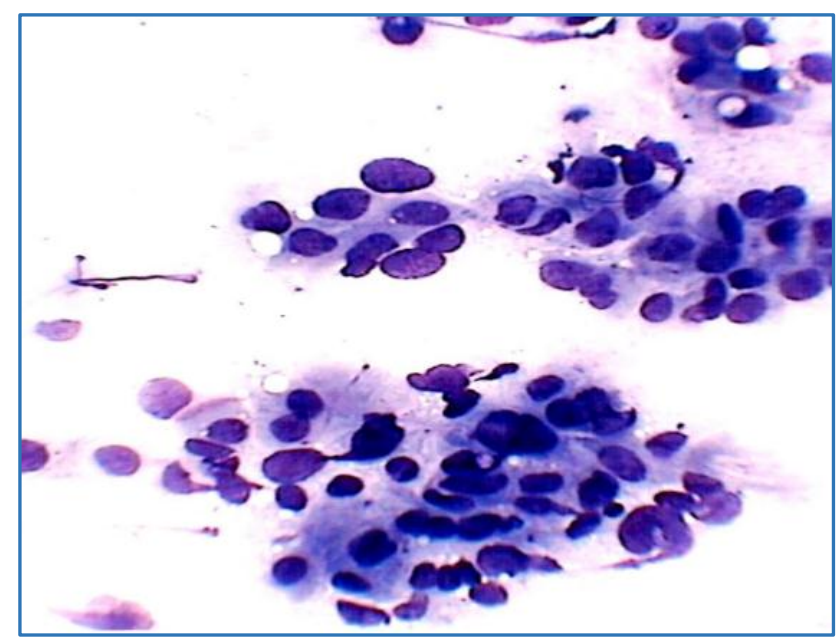

Figure 7. FNAC showing Metastatic Adenocarcinoma

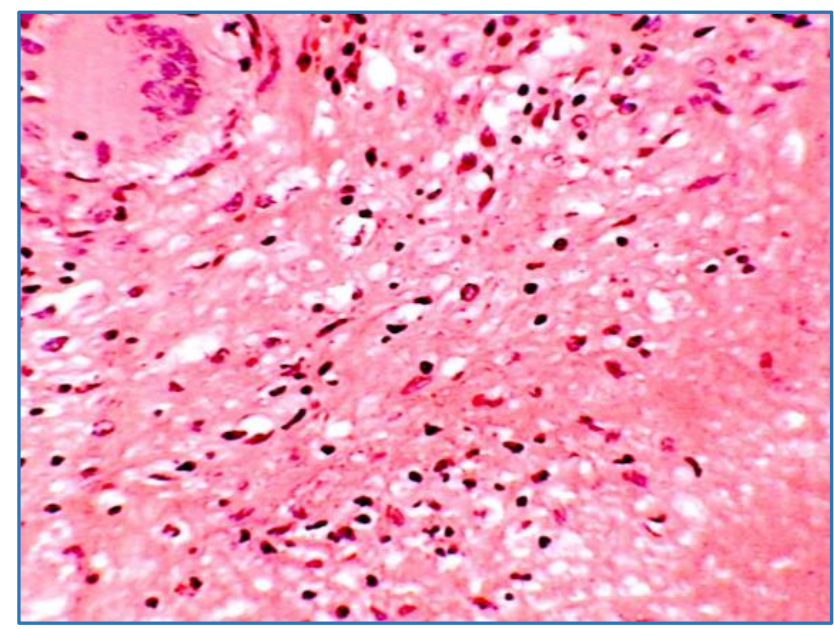

Figure 8. Photomicrograph showing Caseating Tuberculous Lymphadenitis 


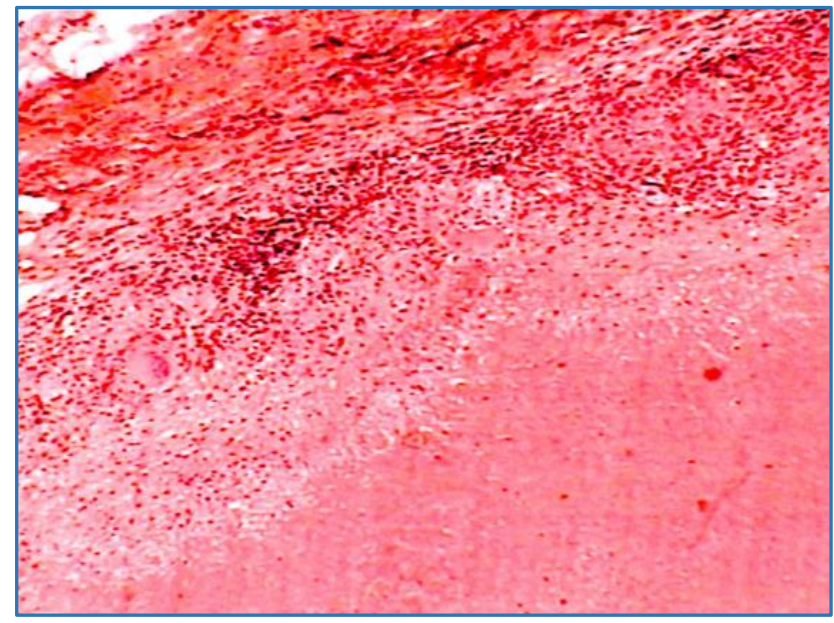

Figure 9. Photomicrograph showing Massive Caseating Tuberculous Lymphadenitis

\begin{tabular}{|c|c|c|c|}
\hline Group & $\begin{array}{c}\text { Type of } \\
\text { Lesions }\end{array}$ & $\begin{array}{c}\text { No. of } \\
\text { Cases }\end{array}$ & Percentage \\
\hline I & Benign & 35 & $70 \%$ \\
\hline II & Malignant & 15 & $30 \%$ \\
\hline \multicolumn{3}{|c|}{ Table I. Distribution of Cases } \\
& Proven Histopathologically \\
\hline
\end{tabular}

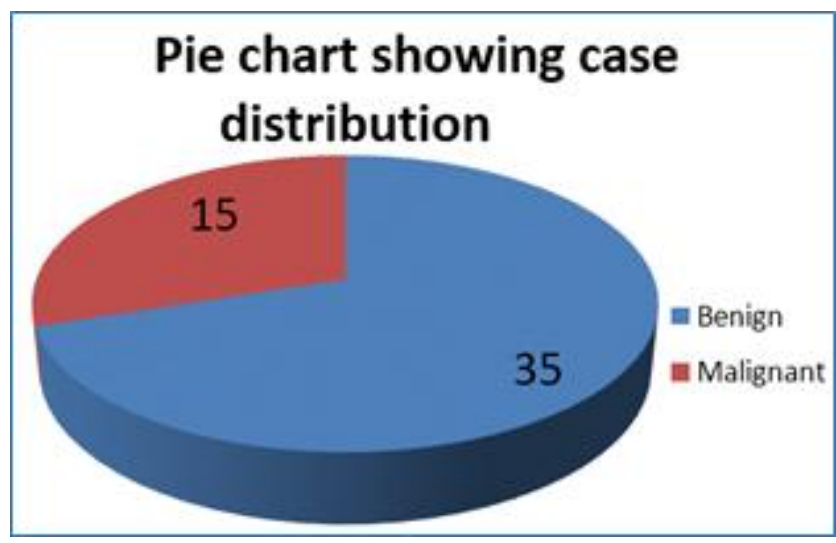

\begin{tabular}{|c|c|c|c|c|c|}
\hline Lesions & Diagnosis & Histology & & Cytology & \\
\hline & & No & $\%$ & No & $\%$ \\
\hline \multirow{2}{*}{ Benign } & Tubercular & 22 & 62.8 & 19 & 63.3 \\
\hline & Non-Specific & 13 & 37.1 & 11 & 36.6 \\
\hline \multirow{3}{*}{ Malignant } & $\begin{array}{l}\text { Squamous Cell } \\
\text { Carcinoma }\end{array}$ & 6 & 40 & 4 & 30.7 \\
\hline & Adenocarcinoma & 8 & 53.33 & 8 & 61.5 \\
\hline & $\begin{array}{c}\text { Non-Hodgkin's } \\
\text { Lymphoma }\end{array}$ & 1 & 6.66 & 1 & 7.6 \\
\hline
\end{tabular}

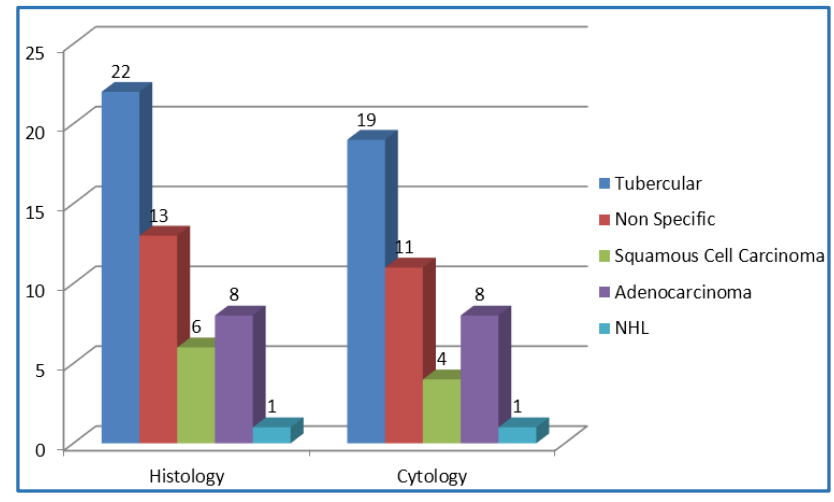

Bar Chart showing Cytology and Histology Correlation of Lesions

\begin{tabular}{|c|c|c|c|c|}
\hline \multirow{2}{*}{ Sex } & \multicolumn{2}{|c|}{ Benign } & \multicolumn{2}{c|}{ Malignant } \\
\cline { 2 - 5 } & No & \% & No & \% \\
\hline Male & 23 & 65.71 & 9 & 60 \\
\hline Female & 12 & 34.28 & 6 & 40 \\
\hline Total & $\mathbf{3 5}$ & $\mathbf{1 0 0}$ & $\mathbf{1 5}$ & $\mathbf{1 0 0}$ \\
\hline \multicolumn{3}{|c|}{ Table III. Sex Distribution } \\
\hline
\end{tabular}

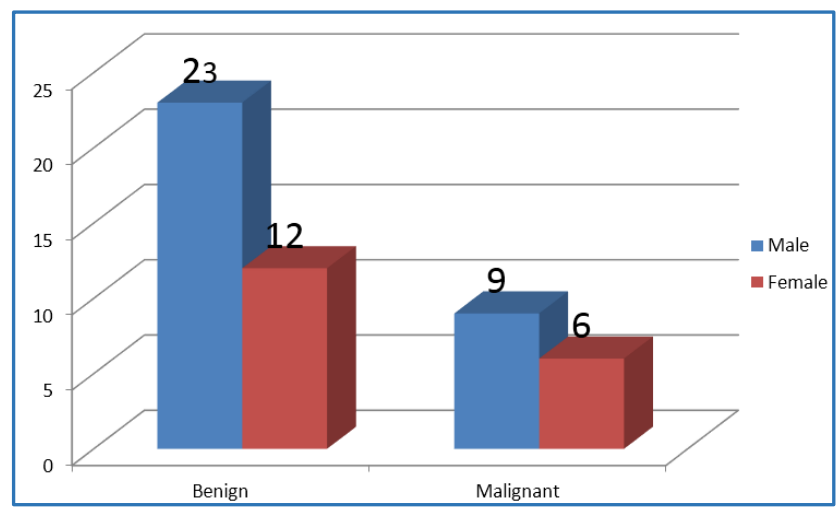

Bar Chart showing Sex Distribution

\begin{tabular}{|c|c|c|c|c|c|c|}
\hline \multirow{2}{*}{$\begin{array}{c}\text { Age Group } \\
\text { In Years }\end{array}$} & \multicolumn{2}{|c|}{ Benign } & \multicolumn{2}{c|}{ Malignant } & \multicolumn{2}{c|}{ Overall } \\
\cline { 2 - 7 } & No & $\mathbf{\%}$ & No & $\mathbf{\%}$ & No & $\mathbf{\%}$ \\
\hline $15-25$ & 10 & 28.57 & 0 & --- & 10 & 20 \\
\hline $26-35$ & 15 & 42.85 & 2 & 13.33 & 17 & 34 \\
\hline $36-45$ & 8 & 22.85 & 4 & 26.66 & 12 & 24 \\
\hline $46-55$ & 2 & 5.71 & 6 & 40 & 8 & 16 \\
\hline Above 55 & --- & --- & 3 & 20 & 3 & 6 \\
\hline Total & $\mathbf{3 5}$ & $\mathbf{1 0 0}$ & $\mathbf{1 5}$ & $\mathbf{1 0 0}$ & $\mathbf{5 0}$ & $\mathbf{1 0 0}$ \\
\hline \multicolumn{8}{|c|}{ Table IV. Age Distribution } \\
\hline
\end{tabular}

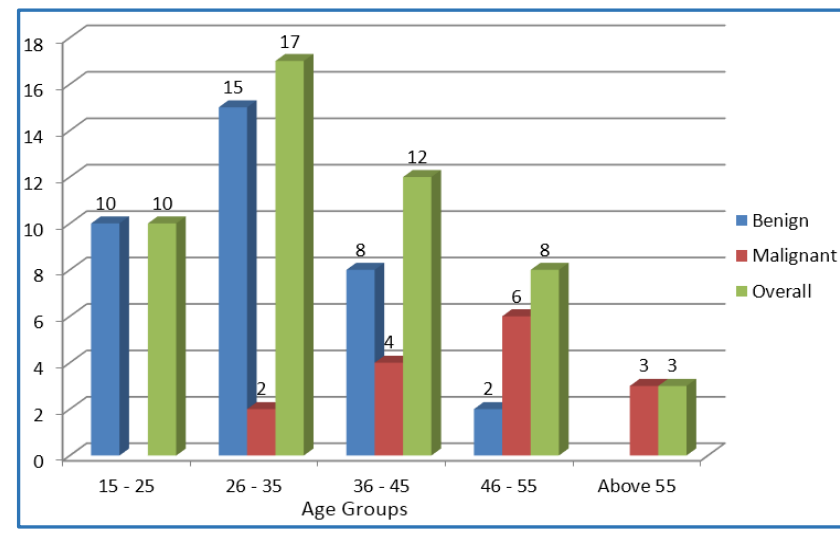

Bar Chart showing Age Distribution 


\begin{tabular}{|c|c|c|c|c|}
\hline \multirow{2}{*}{ Clinical Manifestations } & \multicolumn{2}{|c|}{ Benign } & \multicolumn{2}{c|}{ Malignant } \\
\cline { 2 - 5 } & No & \% & No & \% \\
\hline Neck Swelling & 35 & 100 & 15 & 100 \\
\hline Pain & 4 & 11.42 & 3 & 20 \\
\hline Fever & 15 & 42.85 & 4 & 26.66 \\
\hline Cough \& Expectoration & 10 & 28.57 & 2 & 13.33 \\
\hline Nasal Problem & 6 & 17.14 & 1 & 6.66 \\
\hline Difficulty in Swallowing & - & - & 3 & 20 \\
\hline Change of Voice & - & - & - & - \\
\hline Lump with Pain Abdomen & - & - & 2 & 13.33 \\
\hline Groin Swelling & - & - & - & - \\
\hline \multicolumn{2}{|r|}{ Table V. Clinical Presentation } \\
\hline
\end{tabular}

\begin{tabular}{|c|c|c|c|c|}
\hline \multirow{2}{*}{ Location } & \multicolumn{2}{|c|}{ Benign } & \multicolumn{2}{|c|}{ Malignant } \\
\hline & No & $\%$ & No & $\%$ \\
\hline Jugulodigastric & 18 & 51.42 & 5 & 33.33 \\
\hline Jugulo-omohyoid & 4 & 11.42 & 1 & 6.66 \\
\hline Submandibular & 5 & 14.28 & 2 & 13.33 \\
\hline Supraclavicular & 1 & 2.85 & 4 & 26.66 \\
\hline Combined & 7 & 20.00 & 3 & 20 \\
\hline Total & 35 & 100 & 15 & 100 \\
\hline \multicolumn{5}{|c|}{ Table VI. Location of Palpable Lymph Nodes } \\
\hline
\end{tabular}

\begin{tabular}{|c|c|c|c|c|c|c|c|c|}
\hline \multirow{3}{*}{ Group } & \multicolumn{4}{|c|}{ Unilateral } & \multicolumn{2}{|c|}{ Bilateral } & \multicolumn{2}{|c|}{ Combined } \\
\cline { 2 - 9 } & $\mathbf{2 i g h t}$ & \multicolumn{2}{|c|}{ Left } & \multirow{2}{*}{ No } & No & $\%$ \\
\cline { 2 - 9 } & $\mathbf{N o}$ & $\mathbf{\%}$ & $\mathbf{N o}$ & $\mathbf{\%}$ & & & & \\
\hline Benign & 10 & 28.57 & 20 & 57.1 & 5 & 14.66 & 35 & 70 \\
\hline Malignant & 7 & 46.6 & 6 & 40.0 & 2 & 13.33 & 15 & 30 \\
\hline Total & $\mathbf{1 7}$ & $\mathbf{3 4}$ & $\mathbf{2 6}$ & $\mathbf{5 2}$ & $\mathbf{7}$ & $\mathbf{1 4}$ & $\mathbf{5 0}$ & $\mathbf{1 0 0}$ \\
\hline \multicolumn{8}{|c|}{$\begin{array}{c}\text { Table VII. Unilateral and Bilateral } \\
\text { Enlargement of Lymph Nodes }\end{array}$} \\
\hline
\end{tabular}

\begin{tabular}{|c|c|c|}
\hline No. of Attempts & No & $\%$ \\
\hline $1^{\text {st }}$ & 40 & 80 \\
\hline $2^{\text {nd }}$ & 10 & 20 \\
\hline $3^{\text {rd }}$ & 0 & 0 \\
\hline $\begin{array}{c}\text { Table VIII. No. of Attempts at } \\
\text { Aspiration of Lymph Nodes }\end{array}$ \\
\hline
\end{tabular}

\begin{tabular}{|c|c|c|c|c|}
\hline Diagnosis & Histology & & Cytology & \\
\hline & No & $\%$ & No & $\%$ \\
\hline Benign & 35 & 100 & 30 & 85.71 \\
Malignant & 15 & 100 & 13 & 86.66 \\
\hline Total & $\mathbf{5 0}$ & $\mathbf{1 0 0}$ & $\mathbf{4 3}$ & $\mathbf{8 6}$ \\
\hline \multicolumn{4}{|c|}{ Table IX. Comparison of Diagnostic } \\
Accuracy of Histology and Cytology \\
\hline
\end{tabular}

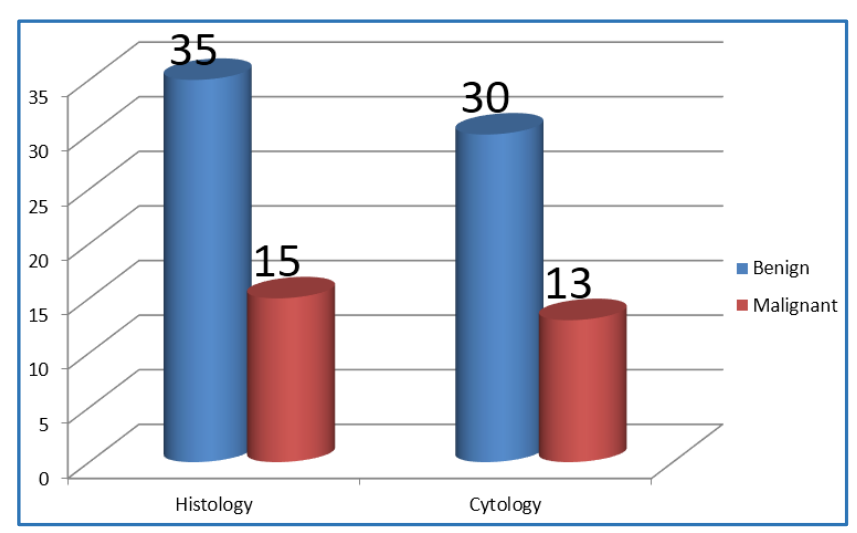

Bar Chart showing Diagnostic Accuracy of Histology and Cytology

\section{DISCUSSION}

Cervical lymphadenopathy (Fig. 1 and Fig. 2) is a commonly encountered condition in clinical practice, which needs prompt and accurate diagnosis for a better prognosis. Fine needle aspiration cytology (FNAC) represents a cost effective and rapid technique for the assessment of nodules and masses within the head and neck area. 6 The well-defined role of FNAC in the investigation of lymphadenopathy has previously been studied. ${ }^{7}$ In the present study, 35 cases (70\%) out of 50 cases were benign in nature whereas 15 cases (30\%) had malignant pathology. This finding is consistent with the finding of Biswas $\mathrm{G}$ et al $(2013)^{8}$ who found an incidence of $71.6 \%$ and $28.3 \%$ respectively. Among the benign causes of cervical lymphadenopathy, the most common was tuberculosis accounting for 22 cases (62.8\%) proven histologically (Fig. 8 and Fig. 9) which may be due to endemicity of disease in India. Moreover, the most common form of extrapulmonary tuberculosis is tubercular lymphadenitis with cervical lymph nodes being most commonly involved group. Cytology could be proven in only 19 cases of tubercular lymphadenopathy (Fig. 4 and Fig. 5). The percentage of cytological accuracy is $86.3 \%$ which is similar to that of Bolch M $(1967))^{9} 80 \%$, Singh JP et al (1987) ${ }^{10} 89.77 \%$, Liang R et al (1990) ${ }^{11} 76.9 \%$, Gupta AK et al (1991) ${ }^{12} 76.78 \%$ whereas Anuradha $S$ and Parthasarathy V (1989) ${ }^{13}$ found $100 \%$ accuracy. In the study of 1396 cases of FNAC of cervical lymphadenopathy, Ramesh Kumar found the most common benign lesion to be tuberculosis (54\%). ${ }^{14}$

In our study, 30 cases $(85.71 \%)$ could be proven cytologically as benign out of the 35 cases of histologically proven benign lymphadenopathy. In the remaining 5 cases, cytology failed to demonstrate due to scanty material during aspiration. In non-specific lymphadenitis, 13 cases were histological proven and 11 cases were cytological proven (Fig. $3)$. The percentage of accuracy of cytology is $84.6 \%$ which is similar to that of Gupta AK et al (1991) ${ }^{12} 76.9 \%$ whereas Anuradha S and Partharsarathy V (1989) ${ }^{13}$ found 100\% accuracy. The different in cytological accuracy may due to whether the samples derive mainly from a germinal centre or from the interfollicular or paracortical tissue of the reactive node (Orell SR et al 1999). ${ }^{15}$

Out of the 14 cases of histologically proven metastatic carcinoma in present study, cytology could be diagnosed in 12 cases (Fig. 6 and Fig. 7). The percentage is being 85.71\%. In 2 cases the cytological diagnosis could not be given due to blood aspirate and cases were proven histologically as squamous cell carcinoma. The accuracy rate is similar to that observed by Bloch M (1967) ${ }^{9}$ 87\%, Frable WJ and Frable MAS (1974) ${ }^{16}$ 96.8\%, Betsill WL and Haldu SI (1980) ${ }^{17}$ 89\%, Sismanis A et al (1981) 18 80\% whereas Anuradha S and Parthasarathy V (1989) ${ }^{13}$ found $100 \%$ accuracy. Overall the diagnostic accuracy in metastatic carcinoma is quite high.

In the present study, one case was diagnosed histologically and cytologically as Non-Hodgkin's Lymphoma. The percentage of cytological diagnosis is $100 \%$ which is quite similar to that obtained by Bloch $\mathrm{M}(1967)^{9} 80 \%$ and Anuradha S and Parthasarathy V (1989) ${ }^{13} 100 \%$.

Cervical lymphadenopathy is most common in young adults. In our study, benign lesions were more common in the age group of 26-35 years (42.85\%) whereas malignant lesions were more common in the age group of $46-55$ years ( $40 \%)$. 
Male cases were more in number than female. Gupta AK et al (1991) ${ }^{12}$ found that tuberculous lymphadenitis was seen more commonly in second and third decades $176.78 \%$ and $63.7 \%$ ). Most common site of cervical lymphadenopathy as observed in the present study was jugulodigastric group of lymph node (46\%). Samar G et al ${ }^{19}$ observed in their study that tubercular lymphadenitis involved mostly the jugulodigastric group of lymph node (33.3\%). Dandapath MC et al20 in their study also revealed that highest tubercular lymph nodes were associated with Jugulodigastric chain.

In our study, unilateral involvement of nodes was more common with $86.00 \%$ (43 cases) than bilateral involvement of nodes with $14.00 \%$ ( 7 cases). Baskota DK et al $(2004)^{21}$ observed unilateral and bilateral disease in $83 \%$ and $17 \%$ cases respectively.

The accuracy rate of aspiration cytology in our study is $86 \%$. Our results are almost in parity with Gertner R et al (1984) ${ }^{22}$ showing accuracy of $85 \%$, Stevenson DS (1989) ${ }^{23}$ found accuracy of 79\% whereas Carroll CMA et al (1998) ${ }^{24}$ found $95 \%$ overall accuracy rate of FNAC when compared to the final histology result.

The accuracy in diagnosis of FNAC depends upon many factors like proper selection of the patients, localisation and aspiration of the affected nodes with good staining and experience of the cytologist. The cause of unsatisfactory smear may be due to scanty cellularity, presence of blood in the aspirated material, presence of purulent material and when the aspiration needle misses the exact site of pathology.

\section{CONCLUSION}

Commonest cause of cervical lymphadenopathy is tuberculosis followed by non-specific lymphadenopathy and metastatic adenocarcinoma. Diagnosis of cervical lymphadenopathy is a team effort of physician, surgeons and the pathologists. Assessment and predicting its clinical behaviour is not an easy task. Fine Needle Aspiration Cytology (FNAC) is a rapid, simple, safe, painless, cost effective diagnostic modality and can be used as a first line of investigatory tool for establishing the aetiology. Hospitalisation of the patient is not necessary and can be performed as an outpatient department or bedside procedure. Its overall correlation in comparison to histopathological study is very high. However, aspiration cytology is not the substitute for histopathological examination but it is one of the weapons to be used to hit the diagnostic target.

\section{REFERENCES}

1. Rains HAJ, Mann CV. The neck. In: Bailey and Love's short practice of surgery. 20th edn. ELBS, London: 1989:648-59.

2. Cheesman AD. The Neck. In: Mann CV, Russell RCG, Williams NS. eds. Bailey and Love's short practice of surgery. 22nd edn. ELBS, London: 1996:497-505.

3. Allhiser JN, McKnight TA, Shank JC. Lymphadenopathy in a family practice. J Fam Pract 1981;12(1):27-32.

4. Raviglione MC, O’Brien RJ. Tuberculosis. In: Fauci AS, Braunwald E, Isselbacher KJ, et al. eds. Harrison's principles of internal medicine. $14^{\text {th }}$ edn. New York: McGraw-Hill 1998:1004-14.

5. Van de Schoot L, Aronson DC, Behrendt H, et al. The role of fine-needle aspiration cytology in children with persistent or suspicious lymphadenopathy. J Pediatr Surg 2001;36(1):7-11.
6. Layfield LJ. Fine needle aspiration of the head and neck. Pathology (Phila) 1996;4(2):409-38.

7. Ghoshal AG, Roy PP. Diagnosis of Tuberculosis. J Indian Med Assoc 2000;98(3):115-8.

8. Biswas G, Das A, Haldar D, et al. Clinico-pathological correlation of cervical lymphadenopathy: a hospital based study. Indian J Otolaryngol Head Neck Surg 2013;65(Suppl 1):S42-S7.

9. Bloch M. Comparative study of lymph node cytology by puncture and histopathology. Acta Cytol 1967;11(2): 139-44.

10. Singh JP, Chaturvedi NK, Das A. Role of fine needle aspiration cytology in the diagnosis of tubercular lymphadenitis. Indian J Pathol Microbiol 1989;32(2): 101-4.

11. Liang R, Loke SL, Ho FC, et al. Histologic subtypes and survival of Chinese patients with Non Hodgkin's lymphomas. Cancer 1990;66(8):1850-5.

12. Gupta AK, Nayar M, Chandra M. Reliability and Limitations of fine needle aspiration cytology of lymphadenopathies an analysis of 1,261 cases. Acta Cytological 1991;35(6):777-83.

13. Anuradha S, Parthasarathy V. Usefulness of Imprint and fine needle aspiration cytology (FNAC) in diagnosis of lymphadenopathies and other tumours. Indian J Pathol Microbiol 1989;32(4):291-6.

14. Kumar RK. Tuberculosis lymphadenitis in children-role of fine needle aspiration cytology. J Assoc Physicians India 1999;47(10):976-9.

15. Orell SR, Sterrett GF, Walters MNI, et al. Introduction, manual and atlas of fine needle aspiration cytology. $3^{\text {rd }}$ edn. London: Churchill Livingstone 1999:1-8.

16. Frable WJ, Frable MA. Thin needle aspiration biopsy in the diagnosis of head and neck tumours. Laryngoscope 1974;84(7):1069-77.

17. Betsill WL, Hajdu SI. Percutaneous aspiration biopsy of lymph nodes. Am J Clin Path 1980;73(4):471-9.

18. Sismanis A, Merriam J, Yamaguchi KT, et al. Diagnostic value of fine needle aspiration cytology in neoplasm of the head and neck. Otolaryngol Head Neck Surg 1981;89(1):62-66.

19. Samar G, Jafari Sh, Mwazamie N. Tuberculosis of cervical lymphadenitis: a clinical, pathological and bacteriological study. Acta Medical Trainica 1998;36(2):138-40.

20. Dandapat MC, Mishra BM, Dash SP, et al. Peripheral lymph node tuberculosis: A review of 80 cases. Br J Surg 1990;77(8):911-2.

21. Baskota DK, Prasad R, Sinha KB, et al. Distribution of lymph nodes in the neck in cases of tuberculous cervical lymphadenitis. Acta Otolaryngol 2004;124(9):1095-8.

22. Gertner R, Podoshin L, Fradis M. Accuracy of fine needle aspiration biopsy in neck masses. Laryngoscope 1984;94(10):1370-1.

23. Stevenson DS, Allison RS, Robertson MS, et al. Aspiration cytology in the diagnosis of head and neck masses: the early Christchurch experience. N Z Med J 1989;102(881):639-41.

24. Carroll CM, Nazeer U, Timon CI. The accuracy of fine needle aspiration biopsy in the diagnosis of head and neck masses. Ir J Med Sci 1998;167(1):149-51. 